OPEN ACCESS

Edited by:

Scott Schaffer,

University of Western Ontario,

Canada

Reviewed by:

Elena Clare Cuffari,

Worcester State University,

United States

Benjamin Kelly,

Nipissing University, Canada

*Correspondence:

Luk Van Langenhove

luk.van.langenhove@vub.be

Specialty section:

This article was submitted to Sociological Theory,

a section of the journal

Frontiers in Sociology

Received: 17 March 2017 Accepted: 09 June 2017

Published: 28 June 2017

Citation:

Van Langenhove L (2017) Varieties

of Moral Orders and the Dual

Structure of Society: A Perspective from Positioning Theory.

Front. Sociol. 2:9

doi: 10.3389/fsoc.2017.00009

\section{Varieties of Moral Orders and the Dual Structure of Society: A Perspective from Positioning Theory}

\author{
Luk Van Langenhove* \\ Institute of European Studies, Vrije Universiteit Brussel, Brussel, Belgium
}

This paper argues that morality is what links structure to agency and that this perspective supports Giddens' point of view that the agency-structure linkage entails not dualism but duality. These claims will be supported by bringing together four mediating concepts to address both how structures come to being and what the substance of structure is. First, John Searle's concept of deontic power and Rom Harré's concept of moral order will be discussed. This will allow to develop a typology of moral orders that distinguishes between cultural, legal, institutional, conversational, and personal moral orders. Second, the notion of field will be presented as a third mediating concept and it will be argued that the different types of moral orders form a latent background that operates as a normative field in which people act. The totality of those nested orders can be pictured as the structure of a society. The final part of the paper will introduce the concept of position, as used in Positioning Theory, as a fourth mediating concept to advance the analysis of moral orders as structures and relate it to the differences in power amongst actors. Here, it will be argued that declarative speech acts are the activators of moral orders, that moral orders enable for certain positions of agency, and that conversational story lines allow to reproduce or change structures.

Keywords: agent-structure, Positioning Theory, social theory, speech acts, moral science

\section{THE AGENT-STRUCTURE PROBLEM}

The agent-structure problem has taken a prominent place in thinking about the ontology of the social realm. ${ }^{1}$ The main issue at stake is what the nature is of the relations between persons as powerful agents and the so-called structural context in which they operate. This debate has, inter alia, led to two competing visions on the social realm: the duality versus the dualism approach. For the proponents of "dualism," such as Archer (1995), social structures exist as emergent properties of individual actions of people. For Archer, the agency and structure are two "separate and opposing things in the world or (...) mutually exclusive ways of thinking about the world" (Craib, 1992, p. 3). In contrast, defenders of "duality," such as Giddens (1984), see structure both as medium and outcome of social action. In other words, for Giddens, structure and agency are just two sides of the coin. But, as noted by Wight (2002) (p. 24), there is still a lot of confusion over what exactly is at stake in the agent-structure problem. Nevertheless, the notion of social structure remains central to the

${ }^{1}$ For some overviews, see Elder-Vass (2010, 2011), Franke and Roos (2010), Porpora (1989), Varela and Harré (1996), Lopez and Scott (2000), and Smith (2010). 
understanding of the nature of the social realm. Many philosophers and social theorists have tackled questions such as What are social structures? What are their origins? And what is the relation between persons or other actors and social structures? Such are all rather general questions and all too often the proposed answers are of an equally general nature. Often it boils down to two opposing visions: there are those who stress the determining power of the structure and there are those who stress the liberty and power of persons. But taking one of those two positions does not allow to clarify how freedom to act rimes with determinism. Also, one can wonder how absolute the structure-agency divide is, as agency cannot be limited to persons as organizations or even states can be considered as agents too. Not surprisingly then, there is a bewildering set of definitions of structure (Wendt, 2015, p. 243), but little agreement on what structure exactly is and how it relates to agency. The most advanced approach comes from Giddens $(1976,1984)$ who introduced the notion of structuration in social theorizing in an attempt to "solve" the agency-structure problem. His solution is that structuration theory treats neither agent nor structure as ontologically prior to the other (Bryant and Jary, 1991).

A key element in the debate is the notion of "emergence," that is "the process of constituting a new entity with its own particular characteristics through the interactive combination of different entities that are necessary to create the new entity, but that does not contain the characteristics present in the new entity" (Smith, 2010 , pp. 25-26). In the natural realm, this process is well known: water $\left(\mathrm{H}_{2} \mathrm{O}\right)$, for instance, has qualities that cannot be reduced to the atoms hydrogen and oxygen. Indeed, where water can extinguish fires, both hydrogen and oxygen do not. On the contrary, they both feed fires. For advocates of critical realism, emergence is the rationale behind the disciplinary autonomy of the different natural sciences (Pratten, 2013). But are there similar processes for the social realm? Is there such social emergence and thus a social realm, the structure, which is not reducible to for instance people? For Archer, the answer to these questions is definitely yes. Giddens (1979) seems to be more nuanced when he states that structuration "involves that of the duality of structure, which relates to the fundamentally recursive character of social life, and expresses the mutual dependency of structure and agency" (p. 69). According to Giddens (1979), the emergent structure can be understood as "non-temporal and non-spatial, as a virtual order of differences produced and reproduced in social interaction" (p. 3). But, as noted by McLennan (1984) (p. 127), it is not at all obvious what this virtual order means. Fligstein and McAdam (2012) have rightly pointed to the "highly abstract" nature of the agentstructure debate. As a result, they argue, "the central concepts of both structure and action remain empirically underspecified" (p. 6). As noted by Lebow (2015) (p. 122), there is indeed a need "to develop a system of mediating concepts that helps explaining the interaction between society and individuals, or agents and structures more generally." A similar observation was already made by Giddens (1979) when he remarked that the idea that action and structure presuppose one another, "necessitates a reworking both of a series of concepts linked to these terms, and of the terms themselves" (p. 53). Giddens certainly contributed himself to filling up this gap with his structuration theory, but the "virtual order" he mentions needs to be more elaborated. Especially, the dynamics of structuration, as it occurs in the interaction between people and structures, should be more developed. And given that these interactions involve linguistic communication, the discursive nature of the mutual dependence of structure and agency could also be further developed. The main purpose of this paper is to propose a refinement of the Giddens' duality of structure notion by introducing the following four mediating concepts: "deontic power," "moral orders," "strategic fields," and "positions."

First, I will present the concepts of deontic power and moral order based upon the work of John Searle and Rom Harré and attempt to integrate their views on the ontology of the social realm and on the moral nature of that ontology into Giddens structuration theory. Bringing in the work of Harré might come as a surprise, as he is known to be very critical toward the notion of social structure. In Harré (2002b), he even calls it a myth and questions that social structures can be causally efficacious. But, as noted by Carter (2002) (p. 134), Harrés target is especially the analytical dualism of Archer. Indeed, Harré does not denies that structures exist, he just sees them as closely linked to people and their interactions and that makes that some of Harrés work can be used to strengthen Giddens' views on the dual structure of society. Second, I will combine the above with some insights from field theory, especially the quantum philosophical take on fields as recently discussed by Wendt (2015). Third, I will inject Positioning Theory to deal with the differences in power between agents. It will be argued that this bringing together of insights from Positioning Theory, linguistic philosophy, and field theory, allows to conceptualize the social realm in such a way that its structure becomes more visible as well as the processes by which actors shape those structures. The central claim developed in this paper is that structures are of moral nature and that agency is limited to intentional actions within the boundaries of what the moral prescripts of structures allow or enable. The analytical framework presented in this paper also aims to draw out the recursive character of social life and the mutual dependence of structure and agency as described by Giddens when he talks of the duality of structure. Finally, it also aims to demonstrate the sociological relevance of Harrés Positioning Theory and stress its empirical relevance to study the overall relevance of concept of morality in understanding the relation between structure and agency.

\section{THE RELEVANCE OF MORALITY}

Haidt (2013) (p. 213) once stated that morality is the key to understanding human behavior. I could not agree more, and in this section I will develop the claim that morality is the missing link between structure and agency. Moral should here be understood as "moral normativity," referring to rights and duties and to judgments about what is right or wrong. Brinkman (2011) (p. 3) has argued that such normativity should be seen as a precondition for all psychological phenomena. Below I will defend the claim that the same holds for all social phenomena and that the social realm cannot be understood if moral normativity is left out. Moreover, moral considerations allow to explain how structures influence 
agents as well as how structures are created through agency. The argument unfolds in two steps.

First, I will defend the Searlean claim that all social structures have one thing in common, namely, deontic speech acts. Second, I will argue that such deontic speech acts have normative effects by creating so-called moral orders. As a result, all social structures can be regarded as moral orders that set out the rules for appropriate behavior. Within this context, agents have the power to either create, adjust to or negate social structures and their moral implications.

The idea that the "substance" of social reality is made-up out of speech acts has been an enduring theme in linguistic philosophy ever since Austin (1961). ${ }^{2}$ For Austin, words are tools that allow people to do things as well as to assert things. It places linguistics at the heart of any endeavor to understand the social realm. ${ }^{3}$ Rom Harré and John Searle have been at the forefront in defending and developing this view. For Harré (1984), "the fundamental human reality is a conversation, effectively without beginning or end, to which, from time to time, individuals may take contributions" (p. 20). Such a species-wide and history-long conversational web is regarded by Harré as the "primary" social reality. This implies that persons and structures are to be regarded as a "secondary" reality: they are products of the conversational reality that is constituted out of speech acts (Van Langenhove, 2011). According to Searle (2009), there is even one specific formal linguistic mechanism that acts as a single unifying principle that constitutes any institutional structure. That principle underlying the ontology of the social realm is the capacity of persons to "impose functions on objects and people where the objects and the people cannot perform the function solely in virtue of their physical structure" (Searle, 2009, p. 7). Searle calls this "status functions" as they imply a collectively recognized status. A piece of paper will count as a 20 EUR bill only if people give that status to that piece of paper. Status functions also carry what Searle calls "deontic power." This is where the moral perspective comes in as deontic powers are all about "rights, duties, obligations, requirements, permissions, authorizations, entitlements, and so on" (Searle, 2009, p. 9). Deontic powers are according to Searle created by a specific sort of illocutionary speech acts, namely, "declarations."

Saying "this house is mine" is a declaration that expresses a status function and gives the speaker a whole set of rights (such

${ }^{2}$ There is an enduring misunderstanding of what the discursive nature of the social reality means. Some theorists and scientists will question this claim by referring to the importance of all sorts of non-discursive or non-solely-discursive practices, like driving a car or entering a pub. But, the discursive approach only stresses that there is a discursive aspect to all human actions. In the case of driving, first there is always an intentional choice to drive and second, people do not only drive on physical roads but also in a space of driving rules that are visible by for instance traffic signs, which can be regarded as speech acts between the authorities and the driver. And finally, the act of driving can be accounted for by the drivers (they can say why, how, and to where they are driving), which entails again speech acts. ${ }^{3}$ Since the seminal work of Austin, cognitive linguistics has developed in different ways. See Harré (2002a) for a review. One interesting strand is the work of Lakoff and Johnson (1980) who deal with the central role of metaphors in understanding the natural and social realm. In a way, the notions of structure and agency as discussed in this paper can be viewed as metaphors to make sense of the social world. See the usage of the concept of "agent" in chemistry or the notion of a load-bearing structure in engineering. as that he can live in the house and decorate it as he pleases) as well as duties (such as paying the mortgage or cleaning it). At the same time, that speech act also has deontic powers toward other people. Visitors of the house, for instance, can stay overnight only when invited, and they are not supposed to take anything away from the house without the consent of the owner.

Searle sees the whole of social structures and the institutionalized reality that goes with it as created by declaration. And he adds that since the invention of written language, declarations can take the form of "standing permanent speech acts" (Searle, 2009, p. 88). Owning a house, as expressed in a written title deed, is an example of such a standing speech act that constitutes property. The same holds for renting a house: a rental contract defines the obligations and benefits for both the landlord and the tenant. The importance of Searle is twofold. One the one hand, he has introduced with his notion of deontology, the issue of morality into the thinking about the institutional reality of structures. On the other hand, he provides a perspective to link structure to speech acts. In this way, Searle (2009) is capable of explaining what exactly is the "construction" in social construction: "the only reality that we can create is a reality of deontology. It is a reality that confers rights, responsibilities, and so on" (p. 89).

People not only create structures, they also need to accept or reject the structure each time a speech act refers to it. Let us take the example of money again. As a structure, the Euro currency, for instance, has been created in 1999. Ever since, all financial transactions in the so-called Eurozone are expressed in terms of Euros. Every time a person pays for a coffee in Euro, this express trust in that currency. If enough people in the Eurozone would lose their trust in the Euro and insist on being paid in Dollars, the Euro would collapse. Keeping a structure alive is thus the work of many. This is in contrast with the power to create a new structure by declaration which is unevenly distributed in society and is related to status functions. Only the heads of state in Europe, for instance, had the power to create the Euro and the accompanying institutions such as the European Central Bank.

When Searle presents the essence of social structures as being a deontologic and therefore of a moral nature, he places himself in a long tradition of looking at the social sciences as moral sciences and of referring to moral orders in the theorization of the social realm. The term "moral science" was first coined by John Stuart Mill in 1843 (Brinkman, 2011, p. 8). Durkheim (1952), for instance, thought of the economy as a social order based upon morality. More recently, scholars such as Douglas (1999) or Wuthnow (1987) have used the concept in their dramaturgical approaches to the study of cultures. Both authors are inspired by the work of Goffman (1967) who pointed to the normative dimension of social order. Wuthnow (1987) defined moral orders as "what is proper to do and reasonable to expect" (p. 14). It is thus about what people judge as being good and bad which in turn relates to rights and responsibilities. Douglas (1999) saw such a moral order as a system of obligations that organize relations among individuals, and regarded this as a central aspect of a society's culture. But it was Harré (1984) who has developed the first systematic theory of moral order in his attempt to describe how the rights and duties of people differ from situation to situation and from context to context. For Harré (1987), a moral 
order is an organized "system of rights, obligations and duties obtaining in society, together with the criteria by which people and their activities are valued" (p. 219). In Harrés view, a moral order has two dimensions: the first represents the rights people have, the second, the locations in space and time that a person can (legitimately) occupy. A policeman, for instance, carries the right to issue parking fines, but only when he is on duty and only in the neighborhood where he is assigned to patrol. If a person only occupies the moral and physical places he or she might occupy, then that person acts is a socially conformist way. Any act that puts one in an "improper" place is a socially deviant act. Harré (1984) pictures society as comprising different moral orders, some of them rather stable, others "quite modest in size and only occasional convened" (p. 246). In other words, while some moral norms can be very universal in a given society, others are the result of locally constructed understandings of rights and responsibilities. As a result, any given culture contains a "multiplicity of interacting and complementary moral orders" (Harré, 1987, p. 220). Moral orders are said to be invisible (Kurri, 2005), as they operate as contexts for individual actions and interactions. It is a set of rules and habits that shape what people can and will do in a certain situation. Traffic rules, such as, the convention that one drives on the left side or the road in the UK, are largely invisible if one is on a country road in the UK. However, traffic signs may make that invisible order visible, and so do the behavior of other drivers that are driving on the left side of the road. When embarking in Dover, the moral order of driving left is made visible very explicit by the "Keep left" sign painted on the road. Moral orders form the social environment in which people act and interact. That interaction is mainly of a conversational nature and involves judgments of what is appropriate to do. Whether an act is labeled as socially confirming or as socially deviant depends on both the meaning assigned to that act in reference to a certain moral order, and on the knowledge the assessor has about justifications or excuses for that act (Semin and Manstead, 1983). Occupying an "improper" place in a moral order can occur either because one does not know that one has no right to "be" there or because one voluntary wants to occupy that place. In the latter case, one can use justifications or excuses that-if accepted-will change the moral order.

Consider the following situation. A person is cooking a meal for his family on Sunday. By doing so, a temporary moral order is created that influences the behavior of the family member. For instance, everybody will be expected to be in the dining room by noon for the aperitif. There is no deterministic obligation to do so, but showing up too late can be considered as impolite and people will be asked to justify their being late. Or taking the aperitif and go away with it to another room might be judged as improper too. But again, there is nothing fixed. Perhaps it is a sunny day and the family agrees to have the aperitif in the garden. So, the moral order can be regarded as a set of habits and prescriptions that allow the people involved to judge what is proper and improper to do or say. Part of it is pre-given: when the family Sunday dinner begins, people know how to behave according to the family tradition. But part of it is constructed during the dinner as conversations develop and certain family traditions can be overruled or changed.
A temporal and local moral order such as the one described above is, however, never the only moral order in play. It is embedded in other moral orders that influence the ongoing interactions as well. For instance, the abovementioned family operates in a more general moral order that deals with how people greet each other. It will be very unlikely that the family members will shake hands when they arrive in the dining room. If it is an Italian family they will eat pasta with a fork. Belgians will use a spoon and fork. Americans will cut the pasta and then eat it with the fork while having their other hand below the table, something that the Belgians would judge to be improper. And next to such general moral orders, there will be other specific moral orders in play as well. Parents and kids, for instance, will each also operate in their own moral orders even when having dinner together. The result is thus that people at all times operate in a complete environment of overlapping and nested set of moral orders that can result in potential conflicts. "Stop playing and finish your meal" might be referring to such a conflict and indicates that the power to "enforce" the dominant moral order is unevenly distributed.

Social structures thus have a moral component: they contextualize everything that people say or do in a framework of normative judgments that can be called moral orders. The above used example of money illustrates well this point. As a social structure a monetary system makes it for most people illegal to print money. And every payment is an act of trust between buyer and seller. But the moral order of a monetary system is never a standalone. It is mashed up with other moral orders, such as the cultural place of money in society. Money can be "owned," "earned," "spent," and so on. All acts that come with moral values, such as that money needs to be earned honestly or that money should not have been thrown away. Rights and duties are thus in a double relationship with structures. On the one hand, structures impose certain rights and duties. On the other hand, there are rights and duties that allow to create structures.

\section{VARIETIES OF MORAL ORDERS}

The focus of Harrés notion of moral orders is on conversational interactions, sometimes referred to as micro-sociology. In contrast, Searle follows a more macro-sociological take. But both have in common that they stress the importance of rights and duties. And both give a central role to speech acts in their endeavor to understand the social realm. In this section I will therefore propose to merge their approaches.

From such a combined Searle/Harré perspective, moral orders can be regarded as sets of rights and duties created by declarations with deontic powers. At any given moment, people live their lives in a multitude of overlapping moral orders. Some of those moral orders are of a very general nature and hardly linked to space and time. Other moral orders can be very specific and active only in specific spaces and/or for limited time-slots only. In both cases (general or specific), moral orders can be latent or active. Latent moral orders are not "in use" in a certain episode. Traffic rules, for instance, have no relevance for a person who is at home. But from the moment that person leaves her home, the traffic rules become an active moral order. 
Harré and Van Langenhove (1999a,b,c) regarded a moral order as "ever shifting patterns of mutual and contestable rights and obligations of speaking and acting" (p. 1) and in doing so implicitly accepted that at any given time people find themselves in one (local) moral order. This needs to be nuanced, as I think that there are always a multitude of moral orders in play. Some are local and very limited in time (for instance, the time of an encounter), but others are more global and enduring. What follows below is an attempt to identify five varieties of moral orders on the dimension general-specific. It is loosely inspired by Parsons AGIL model that allowed him to describe the social realm as consisting out of a cultural system, a social system, a personality system, and a behavioral system (Parsons, 1968).

First, there are the cultural moral orders. They are of a very general nature and can be regarded as the civilizational or cultural aspects of the society in which people live. They include moral opinions that go back to religious or secular codes. The bible, Koran, or Talmud are all powerful reservoirs of values of what is right or wrong. So are the Universal declaration of human rights, national legislations. These moral prescribes often also include meta-values about loyalty to the group and respect toward the hierarchy in the group. And on top of it, there are often sanctions mentioned against those who break the rules.

Cultural moral orders also consist of the many rules, habits, and prescriptions that people take for granted. The practice of greeting each other by shaking hands is a good example. Regardless of the origins of this ritual, it can be expressed as a speech act. It suffices to ask anyone why he or she is shaking hands and one gets answers such as "that is how we greet here." Similarly, children who grow up in a culture where shaking hands is common practice will learn to "properly" do this through the instructions from their parents. And in some cases, specific handshakes are actually invented and communicated to others through speech acts as is the case with the famous secret masonic handshake. The greeting ritual of shaking hands is widely spread around the globe. It is not universal though as there are societies where there exist other greeting rituals, such as rubbing noses. And even though the handshake is used in all Western cultures, there are important local varieties. People in France, for instance, will shake hands more with each other than people in the UK. Knowing when to shake hands and when not is important and most people do have that knowledge. Shaking hands can therefore be seen as part of the cultural moral order that regulates greetings and encounters between people. Not shaking hands in certain occasions can be seen as improper and people involved as, for instance, impolite. Equally so, there are situations where shaking hands would be regarded as odd. As with all moral orders, actors can deliberately choose not to comply. People can refuse to shake hands because they want to act according to another moral order. So, deviance can be understood as putting one moral order above another. And because deviance is possible, change of existing moral orders is possible too. Today more and more people are bumping knuckles instead of shaking hands. Apparently, this is related to opinions about the spread of infectious diseases (Mela and Whitworth, 2014).

Cultural moral orders can be regarded as the umwelt in which people are born and raised. Parents and the educational system both have an enormous power over their infants to impose these orders as taken for granted. Most people will, for instance, adhere to a certain religion because their parents did so as well. As such parents have a big role in reproducing the cultural structure of society.

Second, there are the legal moral orders. At any given time, people are subject to a complex set of laws and legal rules that tell them not to do certain things (e.g., killing someone or ignoring traffic lights) or to do certain other things (e.g., pay taxes or help someone in need). In both cases, not complying with the law can result in penalties, the most dramatic one being executed. Legal norms and procedures are organized at the geospatial level of states or regions (such as is the case within the EU). Legal moral orders are therefore limited to the territory of specific states or regions. Some legal rules will coincide with larger cultural moral orders. Most people will, for instance, not kill other people because they regard it as illegal, but because they have appropriated the cultural norm that it is not right to kill other people. But in many other cases, legal rules are not necessarily seen as morally binding. In those instances, people comply to the law because they want to avoid the punishments. A lot of people will, for instance, link tax cheating to the probability of being caught. Others will regard not paying their taxes as immoral.

The set of legal rules that apply in any given situation is enormous. Legal moral orders therefore are based upon the premise that all people must know all existing legal rules. This is of course a fiction but one that is needed to make the system work. Another assumption is that people bear a responsibility for what they do. Certain categories of people are therefore excluded from complying with the law (e.g., small children or people with severe mental disorders). Next to this, the notion of "legal personality" has been coined. This conceptual tool allows to treat companies, for instance, as if they are persons with a legal and moral responsibility.

Third, there are the institutional moral orders. Whenever people take up membership of a certain organization that comes with a whole set of rules. The concept of institution covers a wide range of social things. Classical examples are business corporations, schools, shops, post offices, or ministries. In the above examples, they all come with a physical correlation, e.g., a school building or a factory. But the institution is more than just buildings. A school only becomes a school when there are pupils and teachers that interact in line with the specific rules and habits that has been formed and that come on top of the cultural and legal moral orders in play. Entering a school or a shop can therefore be regarded as entering a specific institutional moral order. Many institutions are systems of organizations. Take, for instance, any national Higher Education system, it consists of different universities and research funding agencies. And each university in turn consists of different departments. So, being a professor implies being part of different institutional moral orders, including the discipline (chemistry, psychology, etc.) to which one belongs.

Fourth, there are the conversational moral orders. These are created by the participants to a conversation and unless institutionalized will only be existing during the episode of that conversation. Whenever, two or more people meet and engage in a conversation, a local moral order is in play that fine-tunes 
the more general moral orders described above. This is done by declarative speech acts that challenge moral orders that are supposed to be of relevance.

A good example would be a dinner date. There are all sorts of cultural, legal and institutional moral orders in play but the ongoing conversation over dinner fine-tunes these rights and duties. For instance, in a Western culture people only eat the food on their own plate. But one can say "you should try some of my pasta. It is delicious." In some cases, for example, a formal dinner between Heads of State, this would simply be "not done." In other cases, e.g., a meeting between two friends this would be perfectly acceptable. The point is that if the offer to share food is taken up by the other, a certain conversational atmosphere is created that enables other speech acts. A dramatic change in the conversational moral order could occur if one says, for instance, "I think I love you" and the other replies "me too!" Now a whole new set of speech acts and deeds become possible. They can eventually become institutionalized in, for instance, a marriage.

Finally, there are the personal moral orders that emerge out of the internal conversations that people have with themselves. People have at all times internal dialogs in which they can deliberate about what is right or wrong to do. As Harré and Gillett (1994) (pp. 28-29) noted by using the indexical word "I," people create their moral individuality to all whom they are addressing. Even if certain moral orders have been internalized, they still can decide not to act accordingly and do other things.

Together, the above five varieties of moral orders constitute the invisible moral space that surrounds people at all times. Part of that space can be regarded as structure as it involves moral orders that exist independently of the people involved. This is the case for the cultural, legal, or institutional moral order that exists prior to and only to the extent that there is a corpus of recorded speech acts with declarative powers. In other words, structure is a conversational reality to, be it that the conversation is of an abstract nature. In that sense, a simple traffic sign with "stop" on can be regarded as a conversation between a driver and the authorities who issued the traffic rules. As such structure is not to be regarded as a special "level." There is only one level, which is of the species-wide and history-long conversation between people. Another part of the invisible moral space is related to agency as it refers to local conversational or personal moral orders. Here, the normative is created during conversations between people or conversations of an individual with him/herself. People, alone or when talking to others, can design their own moral space. Even in a non-smoking area they can, for instance, agree that it is OK to smoke. The mutual existence of moral orders based upon structure or upon agency therefore accounts for deviance and change. While in theory people have the liberty to do many different things at any time, the actual array of things judged to be proper to do in each situation is limited by the moral orders in play. Some of those moral orders are structural, others are related to agency. And some moral orders have a very strong impact as they prescribe in detail what one should do. Other moral orders have a weaker impact as they leave people a lot of freedom for acting and speaking. But they all have one thing in common: they are of a discursive nature. This perspective also allows to look at agency and structure not as two logically independent concepts that oppose society and persons. Following Vygotsky (1978), one can distinguish on the one hand between the public or private realms and on the other hand between the individual or collective realms. As demonstrated by Harré (1984), this allows one to picture the social realm conceptually as a space with four quadrants constituted by the Cartesian product of the public/private axis and the collective/individual axis. Moral orders can be found in the public/collective domain, as is the case for cultural, legal, and institutional moral orders as well as in the individual/private domain, as is the case for personal moral orders. The conversational moral orders that occur when people talk to each other can be regarded as public/private. Moreover, people can appropriate what is in the public/collective quadrant and make it private/ individual. This is the case when people, for instance, adhere to a religion and feel guilty when not complying to the religious goals. And people can also develop their own moral orders and transfer them to the collective/public realm by behaving accordingly or by publicly accounting for them. The result can be the creation of a new moral order that in turn influences others.

Introducing "deontic powers" and "moral orders" as mediating concepts in the Structure- Agency debate points to the common conversational substance of both agency and structure. The next step is to look at the dynamics of how agency and structure relate to each other. The following section deals with this through introducing the notion of field as a third mediating concept.

\section{MORAL ORDERS AS STRATEGIC FIELDS}

The argument developed so far is thus that both structures and persons (agents) can create certain moral orders through declarative speech acts with deontic powers. An example of how this works for structures is a non-smoking law issued by a government. Such a law can be regarded as a permanent or standing speech act that tells "you are not allowed to smoke in this room." If people do not follow that rule, they can be blamed and even punished. A similar example of how this works at the level of agents could be a group of people that gathers in a place where smoking is allowed. Suppose one of them says "I would appreciate it if we all refrained from smoking." At that time, a new local order is created. So, moral orders of a structural nature are pre-given and can be activated via speech acts. Other moral orders emerge out of conversations and are activated via speech acts as well. The result is that societies can be regarded as a complex and dynamic set of moral orders that together form the "umwelt" of all societal processes. This complexity can be best grasped by metaphorically comparing the moral orders as described above to "fields" in which the speech acts and deeds of people are generated. In this section I will therefore advocate to think of moral orders as being strategic fields. This approach can be related to an interesting alternative for Giddens' structured social theory which is, according to Koivisto (2012) (p. 45), the realist "strategicrelational approach" advanced by Hay (2002) and Jessop (2008). These authors regard structure and agency as analytical categories of which the manifestations are relational. Instead of structure, Hay (2002) (p. 129) talks of "strategically selective context" and instead of agency he prefers to talk about "strategic action." The key focus of the strategic-relational approach is therefore on "the 
relationship between strategic actors and the strategic context in which actors appropriate the environment in which they are situated" (Koivisto, 2012, pp. 45-46).

The technical term "field" has its origins in physics, more precisely in the mid-nineteenth century efforts to blend electricity and magnetism into one theory of electromagnetism based upon the notion of magnetic fields (McMullin, 2002). From there, the theory developed with help of mathematics the concept of "vector fields." Today, our understanding of interactions between fundamental particles is also based upon the notion of fields. Particles are considered to be an excitation (called a "quantum") of a certain field. Such fields are said to have wave properties and those waves can "collapse" into particles. This is the subject of quantum theory, a mathematical framework to predict the outcomes of experiments at subatomic level. Behind the math's of quantum field theory lays still the notion of an "area of influence" (McMullin, 2002, p. 14). The most revolutionary aspect of quantum theory is that the probabilities of finding certain properties in experiments is linked to the act of measurement. Wave functions (which are the expression of the quantum probabilities) are therefore regarded as "potential realities, not actual ones" (Wendt, 2015 , p. 3). The mathematics behind this thinking is huge. But the essence can be captured as follows: subatomic phenomena such as electrons can be regarded both as a particle and as a wave. But the conclusion of many experiments is as Wendt (2015) noted that "as long as the electron is not being observed, it behaves as if it is a wave, and as soon as it is observed it behaves as if it is a particle" (p. 46). Not surprisingly, the terms "field" and "quantum," stripped from their mathematical foundations, made its way to the social sciences.

Lewin (1951) can be credited for introducing field theory in psychology and social theory. But it was Bourdieu (1993) (pp. 72-77) who popularized the notion of field amongst social sciences scholars (Hilgers and Mangez, 2015). He saw the concept of "field" as a social space structured along three dimensions: power relations, objects of struggle, and the rules taken for granted (Pouliot and Mérand, 2013, p. 30). The core of Bourdieu's conception of field is the idea that the social realm is divided into relatively autonomous social subsystems which follow their own "laws" and logic (Bourdieu, 1979, p. 127). Fields can be small or large, more or less important, or more or less autonomous (Pouliot and Mérand, 2013, p. 32).

In recent years, several scholars have attempted to apply quantum thinking to the understanding of psychological and social phenomena. Zohar (1991) and Zohar and Marshall (1994), for instance, have developed popularized accounts of the human mind and of society using quantum physics as a source of inspiration. Others, such as Aerts (2014) have developed more complex views on how quantum theory can contribute to the understanding of psychological phenomena. Wendt (2015) even defended the claim that people are in fact quantum systems.

Inspired by the writings of Bourdieu and Giddens, Fligstein and McAdam (2012) have developed a general theory of social organizations around the notion of "strategic action fields," which they define as "mesolevel social orders" (Fligstein and McAdam, 2012, p. 3) that are the "basic structural building blocks of modern political/organizational life in the economy, civil society, and the state" (Fligstein and McAdam, 2012, p. 3). Within such fields, actors (who can be persons or collectivities) interact with each other based on shared understandings about the purpose of the field, the distribution of power in that field, and the rules to apply. Similar to Russian dolls, they picture such fields as nested and connected in a broader environment of almost countless proximate and overlapping fields. This makes the fields mutually dependent as change in one often triggers change in another field.

Fligstein and McAdam give a special status to the state. They consider a state as a special field that embeds all other fields. But the state is not the ultimate top field. States themselves can be considered as parts of bigger fields. On the one hand, there is the flow of cross-border interactions such as trade, tourism, migration, pollution that can be considered as international strategic fields. On the other hand, states can engage in bilateral and multilateral interactions with other states via diplomacy, agreements, etc. These can again be considered to be strategic fields at a level above the state. In some cases, the field can even be of a global nature as is the case with international law.

The theory of strategic action fields combined with the notion of moral order allows one to picture the social realm as a complex set of partly overlapping or adjacent discursive normative spaces in which people interact either on behalf of an institution or in their own name. The following example illustrates this. When the Belgian Minister of Foreign Affairs addresses the UN General Assembly, he has the authority to speak on behalf of Belgium. As such, he operates in a strategic field, known as the UN multilateral system. Several rules and norms apply in that field, for instance, regarding the time one can speak. But as a person, that Minister also simultaneously belongs to different other moral fields. One of those fields is, for instance, his political party. So, while speaking on behalf of his country, he must make sure that what he says is acceptable for his fellow party members. Meanwhile he can also belong to an ad hoc field amongst UN members, for instance, a group of "friends" of a certain resolution.

To understand how structures operate as moral orders, one can metaphorically compare the relation between persons and structure with the relation between persons and the physical reality. In the latter case, one can say that a person is always surrounded with a material reality. There is the air we breathe, the objects around us, the gravity that prevents us from being detached from the ground. The physical environment in which persons operate limits and influences what they can do. For instance, if there is not enough oxygen in the air, we might find it more difficult to climb stairs. And walking on pebbles is not the same as walking on sand. But at the same time, persons are physical beings as well. So, there are "inner" physical experiences as well. Eating bad food, for instance, will upset our stomach. Another example is that as persons we have physical organs that allow us to perceive parts of the outer reality. We can see things with our hears, but only within a certain spectrum. We cannot hear the radio waves that surround us (unless we use a radio receiver). Structures relate to people in much the same way that physical reality does, while at the same time also being present "within" them. The way this is done is by moral orders: structures envelop people in a unique way as a field of moral orders that limit and influence what people can do at a given time and in certain places. For example, when 
a professor teaches a course, there are several moral orders in play such as the learning goals of the course, the labor contract he signed, his publication track record, the class room dynamics. Nowhere there is a full script of what the professor will talk about, that is his own choice, as long as the moral orders in play allow it. That is the moral order of academic freedom, although a physics professor lecturing about Freud might be a bridge to far and the students might protest. The bottom line is that at any given time, in any given situation people have the freedom to do what they please and say what the like as long it fits in what the moral orders in play allow them to do.

The influence of specific moral orders on people is dependent on the sum of forces of the totality of moral orders in play. For example, for Catholics premarital sex is forbidden but other moral orders might be in play as well. At the end of the day, it will be the personal moral order and the conversational moral order between two people in love, that will determine whether they will comply with their religious norms. So, people can act against the structures in which they operate.

Moral orders can thus be regarded as fields that surround people at any given time. This allows to emphasize that they are at the same time both a background to people as well as a consequence of conversations between people. Combining insights from the moral orders and fields approach with some quantum language allows to reformulate Giddens duality of structure as follows:

1. The social structure of a society consists out of the totality of moral fields that exist at different scales and time slots (e.g., cultural, legal, institutional, conversational, and personal).

2. Each moral field is constituted by declarative speech acts uttered by persons. Moral fields exist at the collective and public level (cultural, legal, and institutional moral orders) as well as at the individual public level (conversations) and at the individual private level (personal moral orders).

3. These moral fields are the invisible space in which persons live their lives. This space has properties of wave functions: the moral fields (and thus the structure) are invisible and latent to the extent that they are present as a potentiality to persons.

4. The agency of persons (or of other actors with personhood properties) consists out of the power to activate certain moral fields by certain declarative speech acts or intentional deeds and their power to place themselves in another moral field.

5. An activated moral field both limits what people can say and do as well as it opens possibilities for saying and doing certain things.

6. Persons (or other actors) have different deontic powers for activating moral orders.

The core metaphor behind the above is thus that moral orders can be regarded as fields of wave functions that are shared nonlocally across time and space. They can collapse into a speech act in much the same way in which at subatomic level wave functions collapse into a particle. An example to illustrate this. When someone utters the speech act "I will drive to work today" and starts her car, this activates the moral order of traffic rules for that person. Of course, this does not mean that the speech act actually needs to be spoken. It is enough that a person decides to drive to work.
She does not need to voice that decision. And even if driving to work has become a daily habit, it supposes a number of acts that when asked "what are you doing?" will result in the speech act "I am driving to work." In other words, it is the intention that counts, whether that intention is voiced as a statement to the family, or just thought by the person, does not matter. In all cases, there is a speech act that activates rules that existed before that speech act, but had no relevance for that person when she was, for instance, having breakfast. When that same person drinks a couple of beers in a local pub after work, the traffic rules might become relevant again, even before driving. People in the pub might say "you have been drinking too much, you should not drive." This then brings other conversational and personal orders in play. This is in line with Wendt's claim that "structures (are) being pulled out of the quantum world of potentiality into the classical world of actuality by agents" (Wendt, 2015, p. 264). As a first consequence, "downward causation in social structures always happens locally, in concrete practices in particular contexts" (Wendt, 2015, p. 264). In other words, the place to look for structure is where people interact, when they engage in conversations. This has since long been claimed by Rom Harré in his attempt to reconcile a scientific realist approach to the study of psychological and social phenomena with a social constructionist approach (Van Langenhove, 2011). For Harré, social structures are nothing more than the products of the acting according to rules, customs or conventions. Hence, social reality is exhausted by what people say and do (Harré, 2002a,b). Wendt (2015) comes to the same conclusion: "There is no higher level in social life above that of individuals: the reality of social life is flat" (p. 265). In that flat social world, people continuously enter and leave different moral orders as they, for instance, drive a car, enter a pub, enroll for a Bachelor program at university, get married, or simply engage in conversations with others. Each time this comes with rights and duties and with judgments about what is good and bad. In that sense, the social world is essentially a moral world.

If one agrees with Wendt and Harrés claim that the social realm is flat and local, structuration needs to be situated in concrete interactions between people. To some extent, Giddens does this, but he does not offer a way to empirically study this from a discursive perspective. Moreover, the issue of power needs to addressed. As emphasized by Bourdieu (1977), there are symbolic struggles over what the distribution of what he calls "capitals" and over what types of capitals count as legitimate within a specific field. The following section will introduce the notion of "position" as a fourth intermediate concept between agency and structure that allows to link structuration to discursive interactions between people. Furthermore, the concept of position will allow to emphasize the role of power in structuration.

\section{STUDYING MORAL FIELDS FROM A POSITIONING THEORY PERSPECTIVE}

So far, this paper has advanced the idea that structure of society can be regarded as a set of moral fields that shape the agency of people. Similarly, the agency of people consists out of their possibility to act against certain moral orders or to create new moral 
orders. Both the shaping of agency and the agency to shape occur in the realm of conversations and interactions between people. The final section of this paper will now introduce the concept of position as used "Positioning Theory" as a theoretical and empirical approach to the study of social interactions that will allow to explain how speech acts form and activate moral orders.

Positioning Theory was first introduced in social sciences by Davies and Harré (1990). ${ }^{4}$ In that paper, positioning activities were regarded as constructs for the discursive production of selves, whereby selves are located in conversations as observably and subjectively coherent participants in jointly produced storylines (Davies and Harré, 1990, p. 48). By presenting positions, speech acts and story lines as "a mutually determining triad," the concept of position became part of a theory that can be situated in the social constructionist movement in the social sciences (Berger and Luckmann, 1966) and the related narrative or discursive turn (Searle, 1995).

Harré and Van Langenhove (1991) presented the first systematic overview of the theory and introduced different conceptual refinements of the theory, such as the differences between first and second order positions, performative and accounting positioning, moral and personal positioning, self and other positioning, and tacit and intentional positioning. In other articles, Positioning Theory was applied to the understanding of stereotypes (Van Langenhove and Harré, 1994), autobiographical talk (Van Langenhove and Harré, 1993a) as well as the writing of scientific publications (Van Langenhove and Harré, 1993b). In 1999, a first edited volume appeared (Harré and Van Langenhove, 1999a) in which the application of Positioning Theory was further broadened to issues such as intergroup relations or national identities. In that same volume, Positioning Theory was advocated as a starting point for reflecting upon the many different aspects of social life (Harré and Van Langenhove, 1999b, p. 10). And indeed gradually, other authors referred to Positioning Theory as framework for mostly social discourse analysis. Examples include the study of teacher-learner interactions, counseling practices, managerial changes processes, public relation policies, and international relations. By 2008, Harré and his collaborators (see Moghaddam and Harré, 2010) were able to claim that the Positioning Theory applications had undergone a very natural expansion of scale, from the analysis of the dynamics of person-to-person encounters to the unfolding of interactions between nation states. Indeed, one specific development has been the application of Positioning Theory to the fields of foreign policy analysis and international relations. Examples include Slocum and Van Langenhove (2003), Slocum-Bradley (2008), and Moghaddam and Harré (2010).

One of the key aspects of Positioning Theory is indeed that it claims to be a dynamic alternative to the more static concept of role. In Harré and Van Langenhove (1999c) (p. 196), this claim is further developed by referring to the Johnsonian notion of determinables and determinants. Roles are determinants; positions are determinable. That is, "a role" is to "a position" as "color"

${ }^{4}$ Interestingly, Giddens (1984) (p. 89) also uses the concept of positioning when he discusses social interaction but he uses it primarily to discuss how actors are positioned along time-space paths. is to "red." Adopting or being assigned a role fixes only a range of positions, positions compatible with the "role." And furthermore, the positions are linked to the unfolding of (conversational) interactions. It is based upon the idea that during conversational interactions, people use narratives or "story lines" to make their words and actions meaningful to themselves and others.

Metaphorically, they can be thought of as presenting themselves and others as actors in a drama, with different "positions" assigned to the players. In this theory, the term "position" refers to "the momentary clusters of rights and duties to speak and act in a certain way" (Van Langenhove, 2011, p. 67). In combination with the speech acts and the story lines of a conversation, the positions form a mutually influencing triangle. In that triangle metaphor, the elements mutually determine one another. The position-the presumptions of rights and duties-influences the meaning given to certain speech acts, while the position and the speech acts influence and are influenced by the story line (Moghaddam et al., 2008, p. 12).

"Positions" in this context are characterized by the adoption of several theoretical devices by which a person and other speakers are presented as standing in various kinds of relations to each other. The positions are thus the parts being performed by the participants. Positions and the accompanying permissible repertoires of acts are linked to the story lines. The actions (including speech) of the participants are given meaning by the story line and the positioning of those involved. Being positioned in a certain way carries obligations or expectations about how to behave. Positions may also carry rights, such as the right to intervene or to speak. As such, Positioning Theory opens perspectives for detailed analysis of discourses, and it is now widely used as an analytical tool to study all kinds of social situations.

The three constitutive elements of the positioning trianglespeech acts, positions, and story lines-reflect the necessary conditions for the meaningfulness of a flow of interactions. Speech acts can have different meanings according to the context, for instance, the phrase "I am sorry" can refer to an apology or can - in the UK-be a request to repeat something what has just been said (Moghaddam et al., 2008, pp. 10-11). A position is the cluster of rights and duties that limits the possible social acts of an entity as it is positioned. It largely determines what an actor is entitled to say given his/her position. Traditions and customs are important sources in the constitution of positions (Moghaddam et al., 2008, p. 11). The third corner of the triangle is occupied by the story lines that structure the flow of actions and interactions in a particular conversation. It relates the positions of two actors who exchange speech acts to each other and creates a certain dynamic of these interactions. Sources of story lines can be histories, persistent media presentations, or traditional plots. An example of a story line is the discourse surrounding "good guys" and "bad guys." It is narratology that studies the origins of the story lines used in a certain culture (Moghaddam et al., 2008, pp. 11-12).

Positioning Theory can be seen as a starting point for reflecting upon the many different aspects of the social realm. If the specieswide and history-long ongoing conversation between people can be regarded as a labyrinth network, Positioning Theory offers a possibility to shift from the perspective of maze traders, those 
who are within the labyrinth, to a perspective of maze viewers, those who can see the labyrinth from above (Harré and Van Langenhove, 1999b, p. 13). Positioning Theory offers an interesting perspective to the Agency-Structure problem supports Giddens notion of "duality of structure." In fact, the positioning triad has been developed as a grammar to investigate the "moral contexts of intentional action" (Harré and Van Langenhove, 1999a, p. iii). The intentional action can be regarded as referring to agency, while the moral contexts can be seen as a reference to structure. Combining the above introduced notions of moral fields and deontic speech acts with the Positioning Theory grammars allows therefore to picture any given social situation as follows:

- First, there are a number of cultural, legal, and institutional moral orders in play that are pre-given and that will assign positions to the actors involved. These positions give certain powers to people.

- Second, there is the developing story line of the conversation that constitutes a local moral order where the initial positions can be confirmed or changed.

- Third, there are the personal moral orders of the actors involved that influence what they will do and say, including refuting and accepting the pre-given positions or the conversationally developed positions.

Positioning Theory also allows to bring in the notions of power to the structure-agency debate. This can be illustrated again by the Sunday dinner example. The members of the family that gathers do so with different powers. First, there are the cultural prescripts that give certain powers to, for instance, the pater families as being the one that cuts the meat or to the oldest person at the table who is entitled to being served first. Second, there are some legal rules in play, such as that underage kid's behavior is the legal responsibility of the parents. Third, the family will have developed certain habits that make their Sunday dinner distinct from other family gatherings. And fourth, each of the family members also bring to the table his/her own moral conventions. On top of that, the powers of the family members might shift during the dinner because of the ongoing conversation or as a result of specific behavior (think, for instance, what can happen when one family member drinks too much wine...).

This implies that the power of structures is never direct. It is, for instance, not an institution that has power, but the actors that represent it and engage in a conversation that exerts the power. Traffic rules do impose speed limits, but one needs either a police officer to use his position to fine someone who drove to fast or one needs an appropriation of the speed limits by a driver who will therefore not drive to fast. This also implies that the power of structures is always relative. If it where absolute, no social change would be possible. Giddens (1976) take on agency is that he sees it as logically tied to poser (p. 110): "the capability of the actor to intervene in a series of events so as to alter their course." And also: "the most seemingly "powerless" individuals are able to mobilse resources so as to carve out "spaces of control" with respect to their day-to-day lives and in respect of the activities of the more powerful" (Giddens, 1982, pp. 197-198). Thompson (1989) (p. 64) has indicated that Giddens cannot clarify the kinds of rules that are relevant to structure without presupposing a criterion of importance and that this criterion cannot be derived from attending rules alone. But people always have the possibility to not confirm to the cultural, state, or group roles. Every time we do something, we create a personal moral order. This is well illustrated by traffic behavior. Most people will think badly about drivers that do not follow the speed restrictions, but when they themselves drive to fast, they will invoke specific reasons to justify their behavior. The personal moral order when sitting in the "bubble" that a car is, often is more powerful than the moral order of traffic rules.

The relationship between deontic speech acts and moral orders is thus never absolute and there is no causal relation between uttering a speech act and its deontic power. While all moral orders are created by deontic speech acts, this will only happen if the moral field in play has no stronger forces toward not activating that moral order. For example, a traffic light in a deserted area of town might be ignored if the driver needs to bring his pregnant wife to a hospital. Also, the forces of a speech act are linked to the position taken up by the one who utters that speech act. That person needs to be in a position that gives him/her the right to utter that speech act. And on top of that for the speech act to have its effect, it needs to be part of a certain story line. In other words, the deontic powers of speech acts are conditional. Take, for instance, the following speech act: "Please, close the door." This speech act has the potential perlucatory force that a door is being closed. But for this to happen, the person who asks to close the door needs to be in a position to have the power to commend someone else to close the door for him. Equally so, that other person needs to be in a position where he can accept and execute that demand. There are many situations possible where rights and duties are so distributed that if A asks to close the door, B will be indeed doing that. Suppose A has broken his leg and has difficulties to stand up, and B is a relative that can walk, it makes sense that he or she will indeed follow-up. However, it could well that even with the right positions of the interlocutors, nothing will happen. Perhaps A was talking in a lecture about Searle's theory and used as an example "close the door." When B understands the story line in play, he or she will not close the door, but just keep on listening...

Using Searle's concepts, this means that deontic speech acts thus derive their normativity from the positions of the actor that utters it, from the story line of the conversation in which the speech act is uttered and from the place that the activated moral order takes in the moral field constituted by all other moral orders in play. This normative power of speech acts is not causal: one speech act does not cause another. Rather, one speech act makes another appropriate or accountable (Harré and Gillett, 1994, p. 33). The interplay between agency and structure can therefore be seen as related to the positions people take at any time: there are the positions that are imposed by the structure and the positions to go against what structures impose. Moreover, people can sometimes be in a position to alter or even create structures. There is no general rule or law that determines what comes first. Only research on specific topics can tell more about the power of structures and agents. 


\section{CONCLUSION}

The structure-agency debate addresses two interrelated issues: how does structure comes to being and what is the substance of structure. This paper has tried to contribute to both issues by injecting a number of intermediate concepts in Giddens' theory of structuration and claims to give answers to both questions. The relation between agency and structure can now be described as follows:

- Societal structures are in essence moral orders that as fields that limit, enable, and influence what people can and should do.

- These moral orders come in different forms, ranging from large cultural spaces to individual belief systems that include appropriated cultural, legal, and institutional orders as well as local orders that emerge through conversations and personal internal conversations. What binds the different moral orders is that they are created by deontic speech acts.

- The totality of moral orders in play when a person enters a certain (conversational) situation can be seen as a moral field that envelops a person and in which the different orders have a certain "valence" toward the individual.

- The agency of people lays both in the possibility of resisting the moral orders in play and in the possibility to create new moral orders.

- These possibilities to resist or create moral orders are related to the power positions of people in their ongoing social interactions.

The above allows to account for both the stability of societies as for the possibility of change and creates a conceptual space for empirical research to understand how people and structures. Moreover, this approach allows to look at the dual structure of society from a single point of view: the moral or normative perspective. When Giddens (1984) presented his views on structuration, he used the Willis (1977) "Learning to Labour" study as an example to show how to apply the duality of structure approach. One of the challenges is to explain how working-class kids get working-class jobs. Willis focused upon how the school system functions and how the joking culture of "the lads" creates a certain moral order. He clearly demonstrated that the school entails a very specific moral order which he labels as the "joking culture." But reference to only the school culture is not enough to explain why in some cases working-class kids do make so-called upward social mobility do make it to better jobs, while others do not. Using the four mediating concepts introduced above, an empirical approach is possible that focuses on the analysis of the moral order of a working-class family and relate it to the broader moral field in which they operate. It is not just the school culture that should be focused upon, but the whole moral field in which the kids grow up. The advantage of such an approach is that the analysis of a family situation can be combined with the broader societal context of that family, including, for instance, how they operate outside the school context, how certain families will have specific moral orders and how those in a position to offer jobs operate in a cultural moral order that uses certain social representations of the concept "working class." Being positioned as a working-class kid is something that happens in many different situations. The challenge is to understand the relations between the situations and the impact of alternative (self-) positions. Again, this is a question to be answered through empirical research. Understanding the duality of structure needs research that does not focus upon a single situation, but needs to take into account the totality of moral orders in play as well as the (power) positions of all those involved. Being a "working-class kid" is not a role but only a position in different conversational contexts (of which the school is only one) and to a certain extent also a self-positioning

This paper tried to advance thinking about the relation between structure and agency by picturing the structure of society as a complex set of partly overlapping and nested moral orders that function as fields in which actors take positions of rights and duties and engage with each other in conversational interactions in which story lines develop that both account for past actions and justify future actions. The moral fields can furthermore be regarded as having quantum properties: they exist as potentialities until activated by speech acts. Taking such a perspective has the advantage of allowing to use a single conceptual framework for studying diverse social structures such as systems of law, economic transactions, and practices such as marriage, and so on. Furthermore, this approach allows to be more precise on how agency and structure relate. Finally, the above also allows to link structure and agency in such a way that "levels" are no longer needed. There is only one level that of conversations and the declarative speech acts that are part of those conversations. They create a complex and constantly changing set of moral fields that surround people at all times. The time and space covered by these fields might differ, but there is no ontological hierarchy between them. Within that realm of conversations, moral orders are potential realities which only become activated when people do or say certain things. Entering a pub, getting married, or simply walking on the street activates numerous moral orders that form together a moral field. The invisible structure that surround us become tangible through speech acts and they are created by declarative speech acts with deontic powers. The strength and durability of such structures depends on the positions of those who utter those speech acts. Agency and structure are thus two manifestations of the fact that the social world is essentially a moral world. This implies that the social sciences should perhaps be regarded as moral sciences again and focus more on what people are "expected" and "supposed" to do and on why they choose either to comply or resist to what the structures of society want or allow them to do.

A better understanding the duality of structure through injecting a moral perspective is possible, but it raises a big question: why are people operating in a structure of moral fields? The answer to this question might be that moral fields allow for the collaboration between people that makes a society run. Such collaboration implies a big division of labor as well as different distributions of power. With the emergence of speech acts some years ago, the Homo sapiens are able to collaborate with others, even those that we do not know. All over the world people are doing things "for me": for instance, the PC I am currently using 
is fabricated by Chinese workers I do not know and designed by people in California I do not know personally either. What connects us is a chain of speech acts from the idea to make an Apple computer to the salesman in the shop that convinced me that buying this particular PC was the best option for me. Homo sapiens is the only species on earth that has organized itself in such huge networks. To be sure, there exist other social animals, but their collaboration remains local. The networks between people have been crystallized in the many human-made objects (including cities) and in a web of institutional facts that span the whole world. It is only thanks to morality that such collaboration is possible as it forms both the glue that holds society together

\section{REFERENCES}

Aerts, D. (2014). Quantum theory and human perception of the macro-world. Front. Psychol. 5:554. doi:10.3389/fpsyg.2014.00554

Archer, M. (1995). Realist Social Theory: The Morphogenic Approach. Cambridge: Cambridge University Press.

Austin, J. L. (1961). How to Do Things with Words? Oxford: Clarendon Press.

Berger, P. L., and Luckmann, T. (1966). The Social Construction of Reality. Garden City, NY: Double Day and Co.

Bourdieu, P. (1977). Outline of a Theory of Practice. Cambridge: Cambridge Univerisity Press.

Bourdieu, P. (1979). La distinction: critique du jugement social. Paris: Les éditions de minuit.

Bourdieu, P. (1993). The Field of Cultural Production: Essays on Art and Literature. Columbia: Columbia University Press.

Brinkman, S. (2011). Psychology As a Moral Science. Perspectives on Normativity. Dordrecht: Springer.

Bryant, C. G. A., and Jary, D. (1991). Giddens' Theory of Structuration. A Critical Appreciation. London: Routledge.

Carter, B. (2002). People power. Harré and the Myth of social structure. Eur. J. Soc. Theory. 5, 134-142.

Craib, I. (1992). Anthony Giddens. London: Routledge.

Davies, R., and Harré, R. (1990). Positioning: the discursive production of selves. J. Theory Soc. Behav. 20, 43-63. doi:10.1111/j.1468-5914.1990.tb00174.x

Douglas, M. (1999). Implicit Meanings: Selected Writings in Anthropology. London: Routledge.

Durkheim, E. (1952). Suicide: A Study in Sociology. London: Routledge. Original version in 1897.

Elder-Vass, D. (2010). The Causal Power of Social Structures. Emergence, Structure and Agency. Cambridge: Cambridge University Press.

Elder-Vass, D. (2011). The causal power of discourse. J. Theory Soc. Behav. 41, 143-160. doi:10.1111/j.1468-5914.2010.00449.x

Fligstein, N., and McAdam, D. (2012). A Theory of Fields. Oxford: Oxford University Press.

Franke, U., and Roos, U. (2010). Actors, structure, process: transcending the state personhood debate by means of a pragmatic ontological model for international relations theory. Rev. Int. Stud. 36, 1057-1077. doi:10.1017/S0260210510000203

Giddens, A. (1976). New Rules of Sociological Method. New York: Harper and Row.

Giddens, A. (1979). Central Positions in Social Theory. London: MacMillan.

Giddens, A. (1982). Profiles and Critiques in Social Theory. London: The Macmillan Press Ltd.

Giddens, A. (1984). The Constitution of Society: Outline of the Theory of Structuration. Cambridge: Polity Press.

Goffman, E. (1967). Interaction Ritual. Essays on Face-to-Face Behaviour. New York: Double Day and Company.

Haidt, J. (2013). The Righteous Mind. London: Penguin Books.

Harré, R. (1979). Social Being. Oxford: Basil Blackwell.

Harré, R. (1984). Personal Being. A Theory for Individual Psychology. Cambridge: Harvard University Press.

Harré, R. (1987). "Grammar, psychology and moral rights," in Meaning and the Growth of Understanding, ed. M. Chapman (Berlin: Springer-Verlag), 219-230. while also creating the spaces for social change. When Haidt (2013) argued that morality binds and blinds, he implicitly made the case for saying that structures bind and blinds. One could add that it is agency that makes that binding and blinding changeable. Or as Harré (1979) once put it: "The task of the reconstruction of society can be begun by anyone at any time in any face to face encounter."

\section{AUTHOR CONTRIBUTIONS}

The author confirms being the sole contributor of this work and approved it for publication.

Harré, R. (2002a). Cognitive Science; A Philosophical Introduction. London: SAGE.

Harré, R. (2002b). Rom Harré on social structure and social change: social reality and the myth of social structure. Eur. J. Soc. Theory 5, 111-123. doi:10.1177/13684310222225333

Harré, R., and Gillett, G. (1994). The Discursive Mind. London: SAGE.

Harré, R., and Van Langenhove, L. (1991). Varieties of positioning. J. Theory Soc. Behav. 21, 393-407. doi:10.1111/j.1468-5914.1991.tb00203.x

Harré, R., and Van Langenhove, L. (1999a). Positioning Theory. Oxford: Basil Blackwell Publishers.

Harré, R., and Van Langenhove, L. (1999b). “The dynamics of social episodes”, in Positioning Theory: Moral Contexts of Intentional Action, eds R. Harré and L. Van Langenhove (Oxford: Basil Blackwell Publishers), 1-13.

Harré, R., and Van Langenhove, L. (1999c). "Epilogue: further opportunities," in Positioning Theory: Moral Contexts of Intentional Action, eds R. Harré and L. Van Langenhove (Oxford: Basil Blackwell Publishers), 195-199.

Hay, C. (2002). Political Analysis. Basingstoke: Palgrave.

Hilgers, M., and Mangez, E. (2015). Bourdieu's Theory of Social Fields. Concepts and Applications. London: Routledge.

Jessop, B. (2008). State Power: A Strategic-Relational Approach. Cambridge: Polity.

Koivisto, M. (2012). Normative State Power in International Relations. Oxford: Oxford University Press.

Kurri, K. (2005). The Invisible Moral Order. Agency, Accountability and Responsibility in Therapy Talk. Jyväskylä: Jyväskylä Studies in Education, Psychology and Social Research.

Lakoff, G., and Johnson, M. (1980). Metaphors We Live By. Chicago: University of Chicago Press.

Lebow, R. (2015). Constructing Cause in International Relations. Cambridge: Cambridge University Press.

Lewin, K. (1951). Field Theory in Social Science. New York: Harper.

Lopez, J., and Scott, J. (2000). Social Structure. Berkeley: University of California Press.

McLennan, G. (1984). Critical or positive theory? A comment on the status of Anthony Giddens. Theory Cult. Soc. 2, 123-129. doi:10.1177/0263276484002 002010

McMullin, E. (2002). The origins of the field concept in physics. Phys. Perspect. 4, 13-39. doi:10.1007/s00016-002-8357-5

Mela, S., and Whitworth, D. E. (2014). The fist bump: a more hygienic alternative to the handshake. Am. J. Infect. Control 42, 916-917. doi:10.1016/j.ajic.2014. 04.011

Moghaddam, F., and Harré, R. (2010). Words of Conflict, Words of War. Santa Barbara: Praeger.

Moghaddam, F., Harré, R., and Lee, N. (2008). Global Conflict Resolution through Positioning Analysis. New York: Springer.

Parsons, T. (1968). The Structure of Social Action. New York: The Free Press. Original version in 1937.

Porpora, D. (1989). Four concepts of social structure. J. Theory Soc. Behav. 19, 195-211. doi:10.1111/j.1468-5914.1989.tb00144.x

Pouliot, V., and Mérand, F. (2013). "Bourdieu's concepts: political sociology in international relations," in Bourdieu in International Relations: Rethinking Key Concepts in International Relations, ed. R. Adler-Nissen (Milton Park: Routledge), 24-44. 
Pratten, S. (2013). Critical realism and the process account of emergence. J. Theory Soc. Behav. 43, 251-279. doi:10.1111/jtsb.12017

Searle, J. (1995). The Construction of Social Reality. New York: Free Press.

Searle, J. (2009). Making the Social World. The Structure of Civilization. Oxford: Oxford University Press.

Semin, G. R., and Manstead, A. S. R. (1983). The Accountability of Conduct. A Social Psychological Analysis. London: Academic Press.

Slocum, N., and Van Langenhove, L. (2003). "Integration speak: introducing positioning theory in regional integration studies," in The Self and Others: Positioning Individuals and Groups in Personal, Political, and Cultural Contexts, eds R. Harré and F. Moghaddam (London: Praeger/Greenwood Publishers), 219-234.

Slocum-Bradley, N. (2008). "Discursive production of conflict in Rwanda," in Global Conflict Resolution through Positioning Analysis, eds F. Moghaddam, R. Harré, and N. Lee (New York: Springer), 207-226.

Smith, C. (2010). What is a Person? Chicago: Chicago University Press.

Thompson, J. B. (1989). “The theory of structuration," in Social Theory of Modern Societies: Anthony Giddens and His Critics, eds D. Held, and J. B. Thompson (Cambridge: Cambridge University Press).

Van Langenhove, L. (2011). People and Societies. London: Routledge.

Van Langenhove, L., and Harré, R. (1993a). “Telling your life: autobiographical talk and positioning," in Discourse and Lifespan Identity, eds N. Coupland and J. Nussbaum (London: SAGE), 359-372.

Van Langenhove, L., and Harré, R. (1993b). "Positioning in scientific discourse," in Anglo-Ukrainian Studies in the Analysis of Scientific Discourse, Reason and Rhetoric, ed. R. Harré (Lewiston, NY: Edwin Mellen Press), 1-20.

Van Langenhove, L., and Harré, R. (1994). Cultural stereotypes and positioning theory. J. Theory Soc. Behav. 24, 359-372. doi:10.1111/j.1468-5914.1994. tb00260.x
Varela, C., and Harré, R. (1996). Conflicting varieties of realism: causal powers and the problem of social structure. J. Theory Soc. Behav. 26, 313-325. doi:10.1111/ j.1468-5914.1996.tb00293.x

Vygotsky, L. S. (1978). Mind in Society: The Development of Higher Psychological Processes. Cambridge, MA: Harvard University Press.

Wendt, A. (2015). Quantum Mind and Social Science. Cambridge: Cambridge University Press.

Wight, C. (2002). "Philosophy of social sciences and international relations," in Handbook of International Relations, eds W. Carlsmaes, T. Risse, and B. A. Simmons (London: SAGE), 14-35.

Willis, P. (1977). Learning to Labor: How Working Class Kids Get Working Class Jobs. New York: Columbia University Press.

Wuthnow, R. (1987). Meaning and Moral Orders. Explorations in Cultural Analysis. Berkeley: University of California Press.

Zohar, D. (1991). The Quantum Self. New York: William Morrow and Company.

Zohar, D., and Marshall, I. (1994). The Quantum Society. New York: William Morrow and Company.

Conflict of Interest Statement: The author declares that the research was conducted in the absence of any commercial or financial relationships that could be construed as a potential conflict of interest.

Copyright (c) 2017 Van Langenhove. This is an open-access article distributed under the terms of the Creative Commons Attribution License (CC BY). The use, distribution or reproduction in other forums is permitted, provided the original author(s) or licensor are credited and that the original publication in this journal is cited, in accordance with accepted academic practice. No use, distribution or reproduction is permitted which does not comply with these terms. 